\title{
Safavid Dynastic Chart
}

Shaykh Safi al-Din (d. I334), founder of the Safaviyye Sufi Order

Shaykh Junayd (d. I460)

Haydar (d. I488), father of Isma'il

ISMA'IL I (I 50I-I 524)

TAHMASB I ( $1524-1576)$

ISMA'IL II ( I 576-I 577)

MOHAMMAD KHODABANDE (I $578-1587$ )

ABBAS I (I 587-I629)

SAFI I (I629-I642)

ABBAS II (1642-I666)

SAFI II (SOLAYMAN) (I 666-I 694)

SOLTAN HOSSAYN (I694-I722)

Afghan Invasion and the Fall of Isfahan

TAMASB II (I722-I732)

ABBAS III (1732-1736) 